\title{
Emergency Cesarean Delivery
}

\author{
Siniša Franjić* \\ Independent Researcher, Herzegovina
}

Submission: July 13, 2020; Published: August 13, 2020

*Corresponding author: Siniša Franjić, Independent Researcher, Herzegovina

\begin{abstract}
Abstarct
The birth of a baby is indeed the most wonderful event in most people's lives, but sometimes childbirth simply does not go as imagined in the family. Most women want to give birth naturally, and few are ready for an caesarean section. Caesarean section is indicated when childbirth is naturally harmful to the mother or for the fetus or for both. It is also indicated in the presence of contraindications for vaginal birth, when such conditions occur in pregnancy or during childbirth that the pregnancy must be to finish urgently, and vaginal delivery is not possible or unsuitable. An emergency caesarean section is sometimes needed to prevent the health complications for the mother or for baby or to save the life of the mother and baby. What can an doctor in Emergency department do when he or she gets a pregnant patient with a particular health problem or problems? He or she must contact the gynecologist, a specialist in obstetrics, as soon as possible which decide what to do. The doctor in ED will thus provide the medical service to the pregnant patient in the best possible way. Both the doctor in ED and the gynecologist obstetrician will undertake such procedures in accordance with the rules of the profession. If they did otherwise, their actions would have enormous health and legal consequences.
\end{abstract}

Keywords: Baby; Mother; Emergency; Cesarean Delivery

\section{Introduction}

An emergency is commonly defined as any condition perceived by the prudent layperson-or someone on his or her behalf-as requiring immediate medical or surgical evaluation and treatment [1]. On the basis of this definition, the American College of Emergency Physicians states that the practice of emergency medicine has the primary mission of evaluating, managing, and providing treatment to these patients with unexpected injury and illness. So what does an emergency physician (EP) do? He or she routinely provides care and makes medical treatment decisions based on real-time evaluation of a patient's history; physical findings; and many diagnostic studies, including multiple imaging modalities, laboratory tests, and electrocardiograms. The EP needs an amalgam of skills to treat a wide variety of injuries and illnesses, ranging from the diagnosis of an upper respiratory infection or dermatologic condition to resuscitation and stabilization of the multiple trauma patient. Furthermore, these physicians must be able to practice emergency medicine on patients of all ages. It has been said that EPs are masters and mistresses of negotiation, creativity, and disposition. Clinical emergency medicine may be practiced in emergency departments (EDs), both rural and urban; urgent care clinics; and other settings such as at mass gathering incidents, through emergency medical services (EMS), and in hazardous material and bioterrorism situations.

In healthcare delivery, we attempt to meet the health and medical needs of the community by providing a place for individuals to seek preventative medicine, care for chronic medical conditions, emergency medical treatment, and rehabilitation from injury or illness [2]. While a healthcare institution serves the community, this responsibility occurs at the level of the individual. Each individual expects a thorough assessment and treatment if needed, regardless of the needs of others. This approach is different than that practiced by emergency managers, whose goal is to assist the largest number of people with the limited resources that are available. As such, emergency management principles are focused on the needs of the population rather than the individual. When either planning for a disaster or operating in a disaster response mode, the hospital should be prepared at some point to change its focus from the individual to the community it serves and to begin weighing the needs of any individual patient versus the most good for the most patients with scarce resources. Moving from the notion of doing the most for each individual to doing the best for the many is a critical shift in thinking for healthcare 
institutions considering a program of comprehensive emergency management. While the initial planning for emergencies by hospitals is focused on maintaining operations and handling the care needs of actual or potential increased numbers of patients and/or different presentations of illness or injury than is traditionally seen, there is also the need to recognize that at some point during a disaster, act of terrorism, or public health emergency there may be an imbalance of need versus available resources. At this point the approach to delivering healthcare will need to switch from a focus on the individual to a focus on the population. This paradigm shift is one of the core unique aspects of hospital emergency management that allows the hospital to prepare to maximize resources in disasters and then to know when to switch to a pure disaster mode of utilizing its limited and often scant resources to help the most people with the greatest chance of survival.

The healthcare delivery system is vast and comprised of multiple entry points at primary care providers, clinics, urgent care centers, hospitals, rehabilitation facilities, and long-term care facilities. The point of entry for many individuals into the acute healthcare system is through the emergency department (ED). Since the late 1970s, the emergency medical services (EMS) system has allowed victims of acute illness and injury to receive initial stabilization of life-threatening medical conditions on the way to the emergency department. Among the many strengths of the ED is the ability to integrate two major components of the healthcare system: prehospital and definitive care. The emergency department maintains constant communications with the EMS system and serves as the direct point of entry for prehospital providers into the hospital or trauma center. Emergency physicians represent a critical link in this process by anticipating the resources that ill and injured patients will need upon arrival at the ED, and initiating appropriate life-saving medical care until specialty resources become available. In this context, the healthcare system is an emergency response entity.

\section{Patient Conditions}

In most emergencies there is no time to disclose the necessary information for an informed consent [3]. Here the providers simply act according to what they think will be in the best interests of the patient. These situations frequently happen in hospital emergency rooms and when emergency medical personnel arrive on the scene of an accident or sudden illness. The emergency exception to informed consent is often quite obvious, but this is not always so. It does not apply, for example, when personnel taking care of somebody in an emergency happen to know what the patient wants. In such a situation they would not do what they think is best for the patient but what they know the patient wants.

It is important to note that the emergency exception that allows physicians to do what they think is best for the patient without obtaining informed consent from the patient or proxy has one major restriction; namely, they cannot do what they think is best if it is otherwise than what they know the patient or proxy wants. Sometimes, for example, emergency department personnel might know from previous admissions that a particular patient from a local nursing home desires only palliative care. If that patient arrives by ambulance at the same emergency department, it is hard to see how it would be morally reasonable for physicians to take aggressive measures to keep the patient alive when, even though there is no time to obtain consent for orders not to attempt resuscitation or not to intubate, they know he or she or a proxy has decided not to have aggressive life-sustaining measures performed.

Patients accessing emergency care services can present with complaints that are extremely diverse, and the way doctors, nurses and paramedics elicit information from patients predominantly focusses on obtaining biomedical details [4]. In some cases, this approach is warranted, as the urgent need to identify signs and symptoms of life-threatening illness or injury is paramount. Yet, $90 \%$ of patients accessing emergency services are not critically ill or injured but seek help and advice. In addition to seeking advice, patients may also be anxious, frightened, intoxicated, misusing drugs or have unhealthy lifestyles. They may have psychosocial reaction to physical disease or vice versa - physical illness such as irritable bowel syndrome, asthma, tension headache can be triggered by psychosocial factors. The effects and interpretation of illness will trigger a different response to the individual depending on their view and experiences. All these factors will have different needs and concerns and it is important to elicit these concerns within a consultation. However, it has been found that nurses working in emergency care disregard the potential for anxiety and the need for support and reassurance in patients who are not severely ill or injured. In addition, where communication skills of junior doctors working in emergency departments have been researched, they are found to use approaches considered to be more physician/illness orientated than patient-centred. By way of similarities of patient presentations in the pre-hospital setting, this could equally be assumed for paramedic practice.

\section{Pregnant Trauma}

Once the pregnant trauma victim arrives in the emergency room, immediate obstetric assessment, fetal monitoring, and abdominal ultrasound should be performed, if possible, in parallel with the other essential standard resuscitation management [5]. Laboratory tests must be compared to the normal values in pregnancy. Coagulation tests are important as pregnant women are at high risk to develop disseminated intravascular coagulation (DIC), particularly in cases of traumatic placental abruption. Fibrinogen levels are typically elevated in pregnancy and may mask the reduction in fibrinogen that accompanies DIC. Rhesus status should be checked and anti -D antibody administered where appropriate to prevent isoimmunization. Important clinical events that may herald fetal loss are maternal instability, vaginal bleeding, and increased uterine tone. Fetal monitoring is important for both mother and fetus, because when maternal cardiac output drops, the mother's vital signs are initially preserved at the expense of 
uterine blood flow. Therefore, fetal distress may be the first sign of maternal hemodynamic deterioration. Fetal monitoring should be instituted immediately, even if the mother is stable and the fetus less than 24 weeks' gestational age. In the event of fetal distress, intrauterine fetal resuscitation, with optimization of maternal cardiopulmonary status, is the primary goal of management. Left tilt or manual uterine displacement should be continued. Owing to the potential for aortocaval compression and the possible effect on venous return, vascular access is ideally inserted above the level of the diaphragm.

\section{Cesarean Delivery}

Various scenarios which lead to emergent cesarean section can be simulated including umbilical cord prolapse, uterine rupture, failed operative vaginal delivery, or a simple fetal bradycardia [5]. There are several simple models for an abdominal wall which can be placed on a full-body mannequin or pelvis for a cesarean section. Additionally, many of the higher fidelity models now have abdominal covers that can be used to make the necessary abdominal incision, though most do not have a uterus inside. There is a very realistic, but expensive, simulator called C-Celia (Operative Experience) that allows for the provider to perform a complete cesarean section and even simulates operative complications.

The maternal indication for emergency cesarean delivery in initial trauma management is typically as a response to hemodynamic instability and is indicated either to control hemorrhage (placental abruption or uterine rupture), or to reveal and control non-obstetric intra -abdominal bleeding [6]. The presenting symptom of placental abruption or uterine rupture may not be maternal instability but fetal distress. Ultrasound is sensitive in only $50 \%$ of cases, so abdominal CT may be needed. Fetal distress in the absence of placental or uterine injury should indicate cesarean section only in the presence of a viable fetus and maternal hemodynamic stability. In the hemodynamically unstable patient with fetal distress, appropriate maternal resuscitation including fluid administration and the control of hemorrhage is the best approach to improve fetal condition.

If the mother is stable, cesarean delivery should also be performed as a rescue procedure for a stressed/distressed but viable fetus [7]. Documentation of the fetal heart rate should ideally be included as part of the primary survey on a pregnant trauma patient ascertained to be in the third trimester of her pregnancy. Continuous electronic fetal heart rate monitoring usually is initiated with completion of the primary survey in patients with a viable and potentially salvageable baby. When immediate delivery for fetal indications is necessary and no anesthesia is available, cesarean section without anesthesia has been reported in patients with neurogenic shock and a lesion above T10. However, anesthesia is generally required and recommended for all SCI patients undergoing cesarean delivery. The clinician should anticipate the possibility of uterine atony if dopamine is being used to treat neurogenic shock secondary to its uterine relaxant effect.

\section{Placenta Previa}

The incidence of placenta previa depends on the gestational age [8]. Commonly, a placenta found in early gestation to be low-lying or a previa will "migrate" away from the cervix with increasing gestational age. At term, incidence among large observational studies has ranged from approximately 1 in 200 to 1 in 400 . Known risk factors include advancing maternal age, multiparity, previous cesarean section, and smoking. Placenta previa is associated with an increased risk of preterm delivery, fetal growth restriction, fetal anomalies, and perinatal mortality. Previa is responsible for $7 \%$ of maternal pregnancy-related deaths due to hemorrhage. In addition, placenta previa is associated with the spectrum of conditions of abnormal implantation of the placenta: placenta accreta, increta, and percreta. In these conditions, the placenta is invasively attached deeply to the myometrium of the uterus or beyond-to the uterine serosa or to adjacent organs such as the bladder or bowel.

If the patient has a placenta previa, cesarean delivery is necessary [9]. For placenta previa, the patient will bleed only when the cervix begins to dilate. As such, the patient will not bleed if not in labor. The goal for the obstetrician is to allow the fetus to mature in utero as long as possible, but not so long as to allow the mother to begin to labor and to hemorrhage. If the patient has a placenta abruption, delivery may be by vaginal or cesarean delivery. Placental abruption is the leading cause of disseminated intravascular coagulation. Therefore, coagulation studies and platelet count should be followed if placental abruption is suspected.

\section{Anesthesia}

Emergency Cesarean section is done to avert potential loss of life of the mother, newborn or both [10]. Good multidisciplinary communication is pivotal in the management of an emergency Cesarean section for good feto-maternal outcome. A four-point classification of urgency of Cesarean section, similar to that used by the National Confidential Enquiry into Perioperative Deaths, has been validated and accepted by anesthetists and obstetricians based on theoretical and actual scenarios. Categories 1 (Immediate threat to life of woman or fetus) and 2 (Maternal or fetal compromise, not immediately life-threatening) are considered as emergency Cesarean section is while Category 3 case (e.g. a woman who has booked for an elective Cesarean section but goes into labor ahead of her scheduled operation date) is no longer elective, but neither is this a true 'emergency' scenario.

Anesthesia for emergency Cesarean section can pose many challenges to the attending anesthetist. One of the greatest challenges for an unprepared attending is to be compelled to administer general anesthesia under less than ideal conditions to an unfasted parturient. This predicament can often be avoided if 
anesthetist is informed earlier about the existence of such 'highrisk' cases before the rapid deterioration of the maternal-fetal clinical state and the decision for Cesarean section is finally made. This would serve to enhance the preparedness of the attending and operating theatre staff in the eventuality of Cesarean section.

Being a complex multidisciplinary procedure, it has been recommended that Caesarean section should be ready to be performed within 30 minutes of decision-to-operate is made. It has been suggested that most of the emergency Cesarean sections can be performed under regional anesthesia. For the parturient with epidural catheter in labor, the anesthetic technique of choice will be to top-up the epidural. If this is contra-indicated, a single shot spinal anesthesia will be appropriate for most of the women laboring without labor epidural catheter. Whether the top-up should be administered in delivery room or theatre is controversial. Topping-up in the delivery room might gain time, but maternal monitoring is suboptimal when the risk of high block or systemic local anesthetic toxicity is greatest. Waiting until arrival in theatre before starting to top-up can invoke obstetrician impatience and a call for general anesthesia.

\section{Hospital Resources}

The resources that are available at a particular hospital and whether it is a community or a teaching hospital may have a bearing on CS rates [11]. Some reports have shown that fetal distress is three times more likely to be diagnosed at a teaching hospital than in a community hospita1. This in part reflects the fact that teaching hospitals handle more women with high-risk pregnancies and may have greater availability of fetal monitoring. Further, community hospitals may lack the resources for an emergency CS that are thought to be required for management of a trial of labor in those women who have had a previous CS. Although these valid reasons might explain why teaching hospitals have higher CS rates, there is still a suspicion that those practicing in such institutions may have an inherent tendency to prefer CS when faced with a choice.

Other factors include the availability of neonatal facilities and an epidural service. The effect of epidural analgesia on labor remains controversial. Some have reported that an on-demand epidural service does not affect the primary CS rate while others have claimed that epidurals increase it. Clearly, these types of resources are likely to be extremely limited in developing coun tries, and as such it is easy to see how these factors would result in a lower $\mathrm{CS}$ rate.

\section{Responsibility of the Physicians}

The aim is to provide excellence in emergency department (ED) care by cultivating the following desirable habits [12]:

a) Listen to the patient.

b) Exclude the differential diagnoses ('rule out') and refine the possible diagnosis ('rule in') when assessing any patient, starting with potentially the most life-or limb-threatening conditions, and never trivializing.

c) Seek advice and avoid getting out of depth by asking for help.

d) Treat all patients with dignity and compassion.

e) Make sure the patient and relatives know at all times what is happening and why, and what any apparent waits are for.

f) Maintain a collective sense of teamwork, by considering all ED colleagues as equals whether medical, nursing, allied health, administrative or support services.

g) Consistently make exemplary ED medical records.

h) Communicate whenever possible with the general practitioner (GP).

i) Know how to break bad news with empathy.

j) Adopt effective risk management techniques.

The duty of care is a physician's obligation to provide treatment according to an accepted standard of care [13]. This obligation usually exists in the context of a physician-patient relationship but can extend beyond it in some circumstances. The physicianpatient relationship clearly arises when a patient requests treatment and the physician agrees to provide it. However, creation of this relationship does not necessarily require mutual assent. An unconscious patient presenting to the ED is presumed to request care and the physician assessing such a patient is bound by a duty of care. The Emergency Medical Treatment and Active Labor Act (EMTALA) requires ED physicians to assess and stabilize patients coming to the ED before transferring or discharging them. Such an assessment presumably creates the requisite physician-patient relationship.

When caring for a patient, a physician is obligated to provide treatment with the knowledge, skill, and care ordinarily used by reasonably well-qualified physicians practicing in similar circumstances. In some jurisdictions, these similar circumstances include the peculiarities of the locality in which the physician practices. This locality rule was developed to protect the rural practitioner who was sometimes deemed to have less access to the amenities of urban practices or education centers. However, the locality rule is being replaced by a national standard of care in recognition of improved information exchange, ease of transportation, and the more widespread use of sophisticated equipment and technology.

Establishing the standard of care in a given case requires the testimony of medical experts in most circumstances, unless the breach alleged is sufficiently egregious to be self-evident to the lay jury member-for example, amputating the wrong limb or leaving surgical implements in the operative field. A physician specializing in a given field will be held to the standard of other specialists in the same field, rather than to the standard of nonspecialists. 
To be eligible to receive federal funds such as Medicare and Medicaid, hospitals with an emergency department must offer emergency and stabilizing treatment services to the public without bias or discrimination [14]. The Emergency Medical Treatment and Active Labor Act is a comprehensive federal law that obligates hospitals offering emergency services to do so without consideration of a patient's ability to pay. It's important to note that this obligation does not apply to inpatients or nonemergent conditions. The absence of bias in the delivery of care should not be misunderstood to suggest all hospitals must provide all medical services, but rather the services they choose to offer must be delivered without bias to the individual patient.

A hospital and its entire staff owe a duty of care to patients admitted for treatment [15]. Following an emergency call, the ambulance service has a duty to respond and provide care. Accident \& Emergency (A\&E) departments have a duty of care to treat anyone who present themselves and are liable for negligence if they send them away untreated. Hospitals without an A\&E facility will display signs stating the location of the nearest A\&E department. This ensures that the hospital could not be held negligent if a patient presented and required emergency treatment as the hospital or its staff had never assumed a duty of care. Once a patient is handed over, a duty of care is created between the patient and the practitioner and this cannot be terminated unless the patient no longer requires the care or the carer is replaced by another equally qualified, competent person. It is therefore extremely important that practitioners are aware of their local policies, professional standards and their scope of practice to avoid becoming liable for litigation by putting a patient at risk, delivering ineffective care or breaching their duty of care.

\section{Conclusion}

A cesarean section is the surgical completion of a baby's birth through an incision in the mother's abdomen and womb. If delivery is ongoing and complications occur, then an emergency caesarean section is performed. A caesarean section may also be scheduled in advance if the mother or baby is in a position that it is impossible to complete delivery by vaginal route, but any preplanned caesarean section, regardless of medical condition, is not always considered urgent. Anesthesia is used during a caesarean section. If there is enough time, most often with a pre-planned caesarean section, epidural or spinal anesthesia is used to allow the mother to be alert during the procedure and to see her baby immediately. If a caesarean is urgent and the baby has to give birth quickly, general anesthesia will be used.

\section{References}

1. Jones TR (2011) Approach to the Emergency Department Patient In: Stone CK, Humphries RL (eds.), Current diagnosis and treatment emergency medicine, seventh edition. The McGraw-Hill Companies, New York, USA, pp. 1.

2. Reilly MJ, Markenson DS (2011) Introduction to Hospital and Healthcare Emergency Management. In: Reilly MJ, Markenson D (eds.), Health Care Emergency Management - Principles and Practice, Jones \& Bartlett Learning, Sudbury, USA, pp. 5-6.

3. Devettere RJ (2010) Practical Decision Making in Health Care EthicsCases and Concepts. In: (3rd edn), Georgetown University Press, Washington, USA, pp. 83-84.

4. Gubbins K, Nixon V (2013) Consultation and Communication Skills. In: Nixon V (ed), Professional Practice in Paramedic, Emergency and Urgent Care, John Wiley \& Sons, Ltd, Chichester, UK, pp. 23.

5. Harney KS, Lee CA (2019) Practical Approaches to Simulating Obstetric Emergencies. In: Deering S, Auguste TC, Goffman D (eds.), Comprehensive Healthcare Simulation - Obstetrics and Gynecology, Springer International Publishing AG, Cham, Switzerland, pp. 147-148.

6. Meroz Y, Elchalal U, Rivkind AI (2013) Maternal trauma. In: Ginosar Y, Reynolds F, Halpern S, Weiner CP (eds.), Anesthesia and the Fetus, Blackwell Publishing, John Wiley \& Sons, Chichester, UK, pp. 330-332.

7. Klauser CK, Rodts-Palenik S, Martin jr JN (2010) Acute Spinal Cord Injury. In: Belfort MA, Saade G, Foley MR, Phelan JP, Dildy III GA (eds), Critical Care Obstetrics. In: (5th edn), Blackwell Publishing Limited, John Wiley \& Sons Ltd, Chichester, UK, pp. 231.

8. Plastino KA (2007) Placenta Previa. In: Salyer SW (ed), Essential Emergency Medicine For the Healthcare Practitioner. Saunders, Elsevier, Philadelphia, USA, pp. 541.

9. Gaiser RR (2015) Obstetric Emergencies. In: Ruskin KJ, Rosenbaum SH, Allman K, McIndoe A, Wilson I (eds.), Anesthesia Emergencies. In: (2nd Edn), Oxford University Press, Oxford, UK, pp. 221.

10. Fyneface-Ogan S (2012) Anesthesia for Cesarean Section. In: Salim R (ed), Cesarean Delivery. InTech, Rijeka, Croatia, pp. 48-49.

11. Broadhead TJ, James DK (1995) Worldwide Utilization of Cesarean Section. In: Flamm BL, Quilligan EJ (eds.), Cesarean Section - Guidelines for Appropriate Utilization, Springer-Verlag, New York, USA, pp. 16-17.

12. Brown AFT, Cadogan MD (2011) Emergency Medicine - Diagnosis and Management, Sixth Edition. Hodder Arnold, London, UK, p. 446.

13. Eckerline ChA, Brantley JC (2011) Legal Aspects of Emergency Care. In: Stone CK, Humphries RL (eds.), Current diagnosis and treatmet emergency medicine, In: (7th edn), The McGraw-Hill Companies, New York, USA, pp. 45.

14. Wollf A (2016) Types of Emergency Departments. In: Solheim J (ed), Emergency Nursing - The Profession, The Pathway, The Practice, Sigma Theta Tau International, Indianapolis, USA, pp. 162.

15. Latcham K (2013) Professional and Legal Issues. In: Nixon V (ed), Professional Practice in Paramedic, Emergency and Urgent Care, John Wiley \& Sons, Ltd, Chichester, UK, pp. 135. 

(C) This work is licensed under Creative BY DOI: 10.19080/JGWH.2020.19.556015

\section{Your next submission with Juniper Publishers} will reach you the below assets

- Quality Editorial service

- Swift Peer Review

- Reprints availability

- E-prints Service

- Manuscript Podcast for convenient understanding

- Global attainment for your research

- Manuscript accessibility in different formats ( Pdf, E-pub, Full Tsext, Audio)

- Unceasing customer service

Track the below URL for one-step submission https://juniperpublishers.com/online-submission.php 